\title{
Formation of Thin Films of Organic-Inorganic Perovskites for High-Efficiency Solar Cells
}

\author{
Samuel D. Stranks, * Pabitra K. Nayak, Wei Zhang, Thomas Stergiopoulos, and \\ Henry J. Snaith*
}

crystallinity $\cdot$ morphology $\cdot$ organic-

inorganic perovskites $\cdot$ photovoltaics $\cdot$ precursors

Organic-inorganic perovskites are currently one of the hottest topics in photovoltaic $(P V)$ research, with power conversion efficiencies (PCEs) of cells on a laboratory scale already competing with those of established thin-film PV technologies. Most enhancements have been achieved by improving the quality of the perovskite films, suggesting that the optimization of film formation and crystallization is of paramount importance for further advances. Here, we review the various techniques for film formation and the role of the solvents and precursors in the processes. We address the role chloride ions play in film formation of mixed-halide perovskites, which is an outstanding question in the field. We highlight the material properties that are essential for high-efficiency operation of solar cells, and identify how further improved morphologies might be achieved.

\section{Introduction}

The search for low-cost alternatives to power sources based on fossil fuels has become of paramount importance in light of rising power costs, recent requirements for the reduction of emissions, and in order to enable the electrification of the developing world. Solar photovoltaics (PVs) are potentially suitable alternatives. The International Energy Agency estimates that the total primary energy supply, the sum of all of the world's power supply averaged over the year, will be approximately $20 \mathrm{TW}$ by $2035 .^{[1]}$ In comparison, the power from the sun intercepted by the earth is around $180000 \mathrm{TW}$, meaning that solar energy is a virtually limitless resource. The current PV market is dominated by siliconbased technologies, which are based on high-efficiency mono-

[*] Dr. S. D. Stranks, ${ }^{[+]}$Dr. P. K. Nayak, Dr. W. Zhang,

Dr. T. Stergiopoulos, Prof. H. J. Snaith

Clarendon Laboratory, Department of Physics, University of Oxford Parks Road, Oxford, OX1 3PU (UK)

E-mail: h.snaith1@physics.ox.ac.uk

$\left.{ }^{+}\right]$Current address: Research Laboratory of Electronics Massachusetts Institute of Technology

77 Massachusetts Avenue, Cambridge, MA 02139 (USA)

E-mail: stranks@mit.edu or multi-crystalline solar cells with a record power conversion efficiency (PCE) of incident sunlight to electricity of around $25 \%$. The price per Watt of solar power from silicon PVs has plummeted in recent years, and it can now provide power at costs close to grid parity in some regions. ${ }^{[2]}$ Even if the costs of solar-cell-active materials become negligible, other costs, such as protective casing, wiring, installation, and maintenance, will remain, and therefore the total costs of electricity from solar power could be further reduced most significantly by increasing the PCE. Further price reductions will require a technology that features lower material costs and also higher PCEs.

Organic-inorganic perovskites have the potential to be such a "disruptive" technology. Power conversion efficiencies of PV devices that contain these materials have increased from around $4 \%$ to a certified $20.1 \%$ in the last three years. ${ }^{[3]}$ Based on their efficiency, they are already rivalling established thin-film technologies, such as those based on cadmium telluride (CdTe) and copper indium gallium selenide (CIGS).$^{[4]}$ These perovskites show remarkable optical absorptions across a wide range of the solar spectrum, and a sharp optical band edge, which suggests low levels of disorder. ${ }^{[5]}$ They also exhibit long charge-carrier diffusion lengths $(>1 \mu \mathrm{m})$ relative to the absorption depth of incident light $(\approx 100 \mathrm{~nm}),{ }^{[6]}$ meaning that almost all photoexcited species in the perovskite are able to reach the interfaces from where the charges are then transported through suitable holeand electron-transporting layers to the electrodes. Most of the significant improvements in PCE have been a direct result of improvements in the formation of perovskite films, ${ }^{[3 \mathrm{c}, 7]}$ which 
led to a better film uniformity and larger crystalline domains, thus suggesting that these features are of the upmost importance for achieving high performance.

In this Minireview, we will focus on the materials chemistry aspects of perovskite films. We will present a detailed description of the different methods for the formation of films and the role of the solvent and starting components, clearly highlighting the material properties that are essential for high-efficiency operation of solar cells. We note that there are several other challenges that need to be solved before we will see the deployment of this technology, but those are beyond the focus of the present Minireview and we refer the interested reader to other reports. ${ }^{[8]}$

\subsection{Organic-Inorganic Perovskites}

Perovskites are a family of materials that share a crystal structure with calcium titanate, that is, $\mathrm{ABX}_{3}$ (Figure $1 \mathrm{a}$ ). The predominant three-dimensional hybrid perovskites used in solar cells to date have short-chain organic cations, such as methylammonium (MA; $\mathrm{A}=\mathrm{CH}_{3} \mathrm{NH}_{3}{ }^{+}$), metal cations such as lead $\left(\mathrm{B}=\mathrm{Pb}^{2+}\right)$, and halides $\left(\mathrm{X}=\mathrm{I}^{-}, \mathrm{Br}^{-}, \mathrm{Cl}^{-}\right.$or mixtures). Here, we will focus primarily on $\mathrm{MAPbI}_{3}$ and the mixedhalide analogue, $\mathrm{MAPbI}_{3-x} \mathrm{Cl}_{x}$, although we also direct the reader to the growing number of reports on alternative organic cations, ${ }^{[9]}$ metal cations, ${ }^{[10]}$ and halides. ${ }^{[5 b, 9 c, 11]}$ The Xray diffraction (XRD) spectrum of $\mathrm{MAPbI}_{3-x} \mathrm{Cl}_{x}$ (Figure $1 \mathrm{~b}$ ) shows its tetragonal crystal structure at room temperature $(160-330 \mathrm{~K}) .^{[12]}$

Two dominant structural concepts have emerged for perovskite solar cells: the planar heterojunction (Figure 1c), in which the perovskite is a simple flat layer that is sandwiched between $\mathrm{n}$ - and p-type contacts, and the mesostructured cell (Figure 1d), in which the perovskite infiltrates a mesoporous metal oxide scaffold, which is either an n-type $\mathrm{TiO}_{2}$ layer or an insulating dielectric scaffold, and additionally typically forms a solid absorber layer on top of the scaffold. ${ }^{[7,13]}$ For the mesostructured cell, the mesoporous metal oxide aids the formation of the perovskite film and its uniformity over a large area and, in the case of the scaffold being n-type $\mathrm{TiO}_{2}$, it also assists in the charge extraction in the region near the planar n-type contact. Both concepts (planar and meso) are currently evolving and are likely to eventually

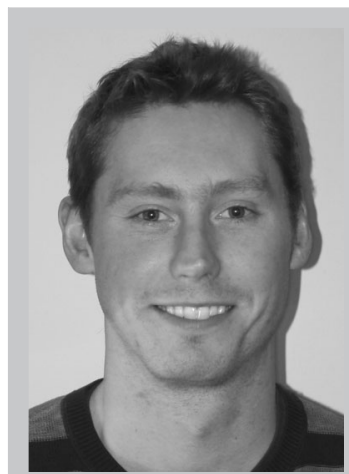

Samuel D. Stranks is a Marie Curie Fellow at the Massachusetts Institute of Technology. He completed his PhD in 2012 as a Rhodes Scholar at Oxford University, working on carbon nanotube/polymer blends. He then worked as a postdoctoral researcher in Henry Snaith's group at Oxford University where he was also a Junior Research Fellow at Worcester College. His research focuses on the optical and electronic properties of emerging photovoltaics.

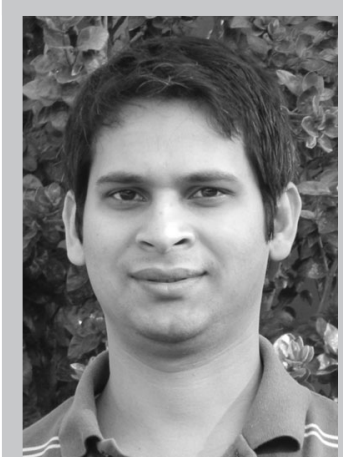

Pabitra K. Nayak received his Ph.D. from the Tata Institute of Fundamental Research, Mumbai, India in 2010. He then worked as a postdoctoral fellow at the Weizmann Institute of Science, Israel. He is currently a postdoctoral research associate at the University of Oxford, where his research interests involve the development of new materials and the modification of interfacial energetics for optoelectronic applications.

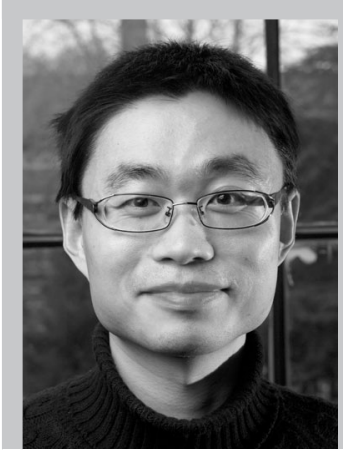

Wei Zhang received his PhD from the National University of Singapore in 2012 and is currently a postdoctoral research assistant in Henry Snaith's group at Oxford University. His main research interests include the development of high-efficiency and low-cost photovoltaic devices ranging from sensitized mesoscopic and hybrid solar cells to perovskite solar cells, and the fabrication of various nanostructures for solar-cell applications.

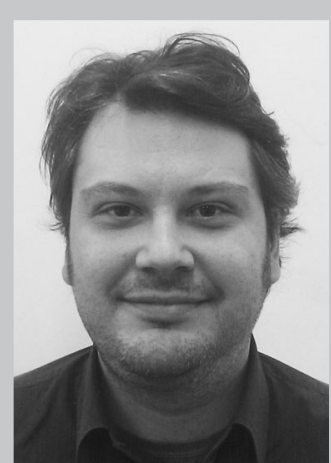

Thomas Stergiopoulos received his PhD in Physical Chemistry from the National Centre for Scientific Research Demokritos in 2006. He recently worked within European projects toward renewable energy and clean environment applications and is currently a Marie Curie Fellow at Oxford University. His research focuses on hybrid technologies for efficient photovoltaics, such as dyesensitized and perovskite solar cells.

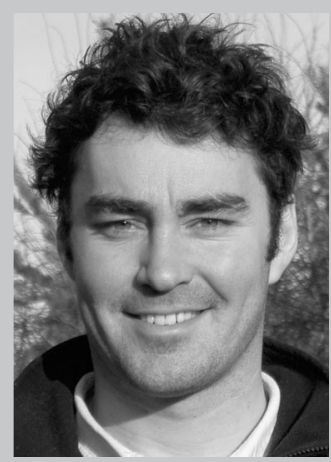

Henry J. Snaith is a Professor of Physics at Oxford University, head of the Photovoltaic and Optoelectronic Device Laboratory, and the chief scientific officer and co-founder of Oxford Photovoltaics. Henry was the recipient of the 2012 Institute of Physics Paterson Medal and the 2014 Materials Research Society Young Investigators Award, and he was named as one of "Nature's Ten" people who mattered in 2013. 
a)
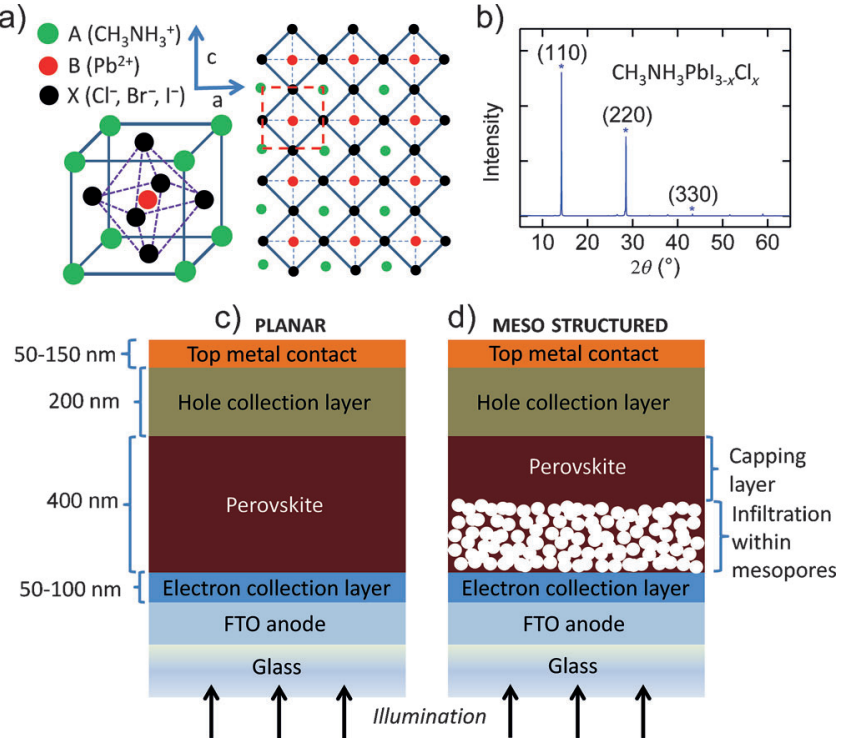

Figure 1. a) Crystal structure of perovskites. b) $X$-ray diffraction (XRD) spectrum of a $\mathrm{CH}_{3} \mathrm{NH}_{3} \mathrm{Pbl}_{3-x} \mathrm{Cl}_{x}$ film prepared by spin-coating of the precursors on a glass substrate and annealing at $\left.100^{\circ} \mathrm{C} .{ }^{[b]} \mathrm{c}, \mathrm{d}\right)$ Schematics representing the planar $\mathrm{c}$ ) heterojunction and d) mesostructured device architectures.

converge in a single architecture. Herein, we will discuss both concepts in the context of perovskite film formation, but we refer the reader to Refs. [8ab] for further details about the architectures. We also note that an "inverted" structure is considered here to be an inverted architecture with respect to that in Figure $1 \mathrm{c}$, that is, in which holes are collected through the bottom electrode.

\section{Deposition Methods}

A number of methods to fabricate thin films of organicinorganic perovskites have emerged, each resulting in varying degrees of surface coverage, and crystal and film quality. Most methods are based on the same principle: the combination of an organic component, such as methylammonium iodide (MAI), with an inorganic component, such as $\mathrm{PbI}_{2}$ or $\mathrm{PbCl}_{2}$, to form the perovskite $\left(\mathrm{MAPbI}_{3}\right.$ or $\mathrm{MAPbI}_{3-x} \mathrm{Cl}_{x}$, respectively). In the following sections, we will describe the films resulting from various deposition methods.

\subsection{One-Step Deposition}

In the simplest formulation, the two precursor salts (metal halide and organic halide) are dissolved in an organic solvent (see Section 3), the mixture is spin-coated onto a substrate, and the perovskite is formed through an annealing process at around $100^{\circ} \mathrm{C}$. The first high-performance devices were obtained following this protocol to deposit the mixture on mesoporous n-type $\mathrm{TiO}_{2}$ or insulating $\mathrm{Al}_{2} \mathrm{O}_{3}$ scaffold substrates, where the scaffolds were themselves on top of a thin ntype compact $\mathrm{TiO}_{2}$ layer. ${ }^{[3 \mathrm{~b}, \mathrm{~d}]}$ However, spin-coating the mixture directly onto the compact n-type contact, as for a)

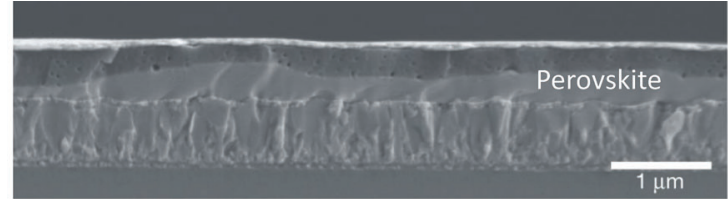

b)

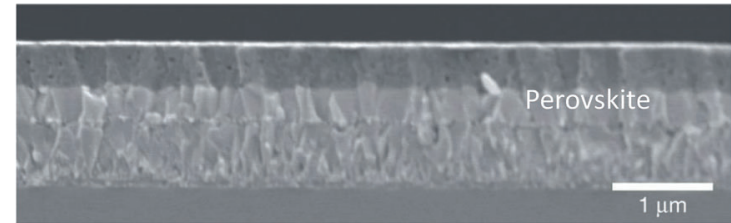

c)

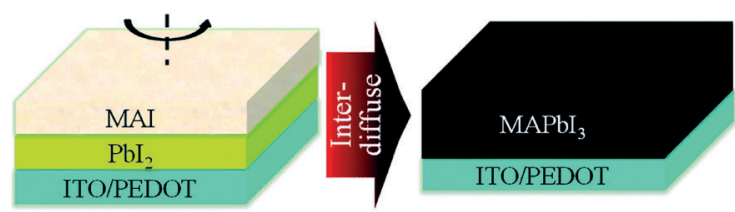

d)

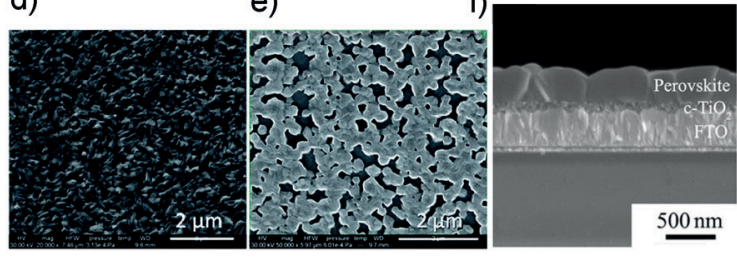

Figure 2. a,b) Cross-sectional SEM images of full devices featuring perovskite films prepared by a) solution processing and b) vapor deposition. ${ }^{[17]}$ c) Schematic of the interdiffusion method. d,e) Top-view SEM images of the films resulting from d) interdiffusion and e) solution-processing. Reproduced from Ref. [19] with permission from The Royal Society of Chemistry. f) Cross-sectional SEM image of a perovskite film prepared using the vapor-assisted conversion (VASP) method. Reprinted with permission from the American Chemical Society, Ref. [20]. SEM = scanning electron microscope.

planar heterojunction architectures, initially resulted in a dewetting effect, ${ }^{[14]}$ thus leading to poor surface coverage (Figure 2e). ${ }^{[13 a, 15]}$ This in turn resulted in poor device performance as a result of low-resistance shunting paths and low light absorption in the solar cell. The surface coverage and device performance are both highly dependent on the processing conditions. We found that processing in a nitrogen atmosphere, optimizing the spin-coating protocol, and lowering the annealing temperature to $90^{\circ} \mathrm{C}$ improves coverage (>90\%) and film morphology, with devices reaching a PCE of more than $12 \% .^{[6 a, 15]}$ Additionally, we have recently shown that a rapid "flash" post-anneal treatment at $130{ }^{\circ} \mathrm{C}$ promotes the growth of highly uniform micrometer-sized textured perovskite domains (PCE of $13.5 \%$ ), while the standard annealing conditions $\left(100^{\circ} \mathrm{C}\right)$ result in polycrystalline perovskite domains of $100-1000 \mathrm{~nm}$ in size. ${ }^{[16]}$

Despite improved coverage, spin-coated films generally show an undulating variation in thickness across the substrates (Figure 2a), which is not ideal for reproducible and optimized device performance. ${ }^{[17]}$ Moving away from solution-based spin-coating techniques, we have shown that highly uniform $\mathrm{MAPbI}_{3-x} \mathrm{Cl}_{x}$ films with nearly $100 \%$ surface coverage can be obtained using a dual-source co-evaporation ${ }^{[18]}$ of $\mathrm{MAI}$ and $\mathrm{PbCl}_{2}$ (Figure $2 \mathrm{~b}$ ), followed by an annealing step at $100{ }^{\circ} \mathrm{C}^{[17]} \mathrm{We}$ achieved a device PCE of 
$15.4 \%$ using this method, again suggesting that uniform films with high coverage are essential for high performance. We note that the perovskite crystals obtained by the vapordeposition technique are a few hundred nanometers in size, and thus smaller than the micrometer-sized platelets obtained from spin-coating. Furthermore, evaporation has the added advantage of being more compatible with multi-junction architectures, for example to process perovskites as top cells for existing silicon technologies, or multiple perovskite junctions. ${ }^{[8 \mathrm{a}, 17]}$

Recently, Barrows et al. demonstrated the use of ultrasonic spray-coating under ambient conditions as a means to fabricate planar heterojunction $\mathrm{MAPbI}_{3-x} \mathrm{Cl}_{x}$ solar cells. ${ }^{[21]} \mathrm{By}$ optimizing the temperature of the substrate during spraycoating and the post-annealing temperature, they were able to achieve reasonable surface coverage $(>85 \%)$ with micrometer-sized platelets, and a device PCE of $11.1 \%$. This result is promising for low-cost, large-area manufacturing.

\subsection{Two-Step Deposition}

Additional control over the morphology can be achieved by sequentially depositing the two precursors. ${ }^{[22]}$ In the "sequential-deposition" method, Burschka et al. first infiltrated a mesoporous $\mathrm{TiO}_{2}$ film with a solution containing $\mathrm{PbI}_{2}$ and subsequently converted the film to $\mathrm{MAPbI}_{3}$ perovskite by exposing it to a solution of MAI. ${ }^{[13 c]}$ The conversion occurred at room temperature within seconds. Devices fabricated using the mesostructured $\mathrm{TiO}_{2}$ architectures achieved a PCE of $15.3 \%$. Without a perovskite capping layer, in which all the perovskite was entirely within the mesoporous $\mathrm{TiO}_{2}$, efficiencies up to $13 \%$ were achieved. ${ }^{[23]}$ We note that the mesoporous scaffold limited the size of the perovskite crystals to around $20 \mathrm{~nm}$.

This method to convert $\mathrm{PbI}_{2}$ to a perovskite has also been demonstrated with solid films of $\mathrm{PbI}_{2}$ for use in planar heterojunction device architectures. Liu and Kelly reported the conversion of thin spin-coated films of $\mathrm{PbI}_{2}$ to $\mathrm{MAPbI}_{3}$ by immersion of $\mathrm{PbI}_{2}$ in solutions of MAI. ${ }^{[24]}$ The absence of the mesoporous layer allowed the unconstrained growth of the perovskite crystallites $(\approx 100-1000 \mathrm{~nm})$ and, by optimizing the MAI concentration, solution temperature, and dipping time, a device PCE of $15.7 \%$ was achieved. Similar highperformance devices were demonstrated by Docampo et al. by immersing the $\mathrm{PbI}_{2}$ films in $\mathrm{MACl}$ instead of MAI. ${ }^{[25]}$ Yongzhen et al. showed that the crystallization of the initial $\mathrm{PbI}_{2}$ layer can be retarded by the use of dimethylsulfoxide (DMSO) as the solvent instead of $\mathrm{N}, \mathrm{N}$-dimethylformamide (DMF), which is typically used, resulting in more controlled particle sizes, more complete conversion, and increased reproducibility of film quality. ${ }^{[26]}$

Aside from conversions in solution, Yang and co-workers demonstrated the vapor-assisted solution processing (VASP) conversion of the $\mathrm{PbI}_{2}$ to $\mathrm{MAPbI}_{3}$ by exposing the film to an MAI vapor ${ }^{[20]}$ (as opposed to MAI in solution). The method produced films with well-defined grain structures with crystallites on the micrometer scale, complete surface coverage, and low surface roughness (Figure $2 \mathrm{f}$ ). The authors demonstrated a device PCE of $12.1 \%$. The advantage of vapor-based conversion over solution-based methods is that dissolution of the already converted perovskite is minimized, generally resulting in smoother films with less faceted crystals.

Xiao et al. recently demonstrated a method in which the precursor materials were sequentially spin-coated as bilayer stacks and the conversion of the perovskite was achieved by "interdiffusion" of the layers, as shown in Figure 2 c. ${ }^{[19]}$ The resulting films showed excellent surface coverage and low roughness (Figure $2 \mathrm{~d}$ ). The highest PCE (15.4\%) was obtained in an inverted solar-cell configuration with a thickness of $\mathrm{PbI}_{2} / \mathrm{MAI}$ of $140 / 190 \mathrm{~nm}$, with annealing at $100^{\circ} \mathrm{C}$ for $2 \mathrm{~h}$. Chen et al. demonstrated further improvements in smoothness using the same method but with sequential thermal evaporation of the precursor layers $\left(\mathrm{PbCl}_{2}\right.$ and MAI). ${ }^{[27]}$ Park and co-workers used this two-step interdiffusion method with a thin mesoporous $(\approx 100 \mathrm{~nm}) \mathrm{TiO}_{2}$ layer; the resulting capping layer of perovskite comprises "cuboid" crystals whose size is strongly dependent on the MAI concentration. ${ }^{[28]}$ They demonstrated a device with a PCE of $17.0 \%$.

\section{Role of the Solvent}

The control of the crystallization and thus the kinetics of film formation during deposition and annealing are the key to the optimization of device performance. Optimal film morphology can only be achieved by successfully manipulating the nucleation and growth of the perovskite, for which "solvent-engineering" is a very effective technique. ${ }^{[7]}$

\subsection{Dissolving Precursors}

For a thin film, high precursor concentrations are required in order to obtain a continuous, dense layer with suitable optical density (typically $>0.5 \mathrm{M}$ ). Suitable solvents for perovskite precursors appear to be limited to highly polar aprotic solvents, such as DMF, DMSO, $\gamma$-butyrolactone (GBL), acetonitrile etc. In the first reports on perovskite solar cells, the precursors were mixed in GBL for $\mathrm{PbI}_{2}{ }^{[3 \mathrm{~d}]}$ or $\mathrm{DMF}$ for the more difficult to dissolve $\mathrm{PbCl}_{2} \cdot{ }^{\left[{ }^{[b]}\right.} \mathrm{DMF}$ can also be replaced by solvents with a similar (e.g. $N$-methylpyrrolidone, NMP) or even higher (e.g. DMSO) dielectric constant, although the surface coverage is quite poor, likely because the employed solvents evaporate more slowly. ${ }^{[15]}$

A typical crystallization trick is the use of a mixed solvent. Liang et al. added 1,8-diiodooctane (DIO) to DMF, which resulted in the formation of films with more uniform crystals and more ordered growth directions. ${ }^{[29]}$ These features, along with the enhanced solubility of $\mathrm{PbCl}_{2}$ (as a result of chelation of $\mathrm{Pb}^{2+}$ with $\mathrm{DIO}$ ), which led to an improved surface coverage, resulted in inverted solar cells with enhanced PCEs (from 9.0 up to $11.8 \%$ with the addition of only $1 \%$ DIO). Likewise, other groups employed mixtures of GBL in DMF (3 vol\%), which mainly influenced the film coverage rather than the crystalline structure of the material, thus leading to improved photovoltaic performance in comparison with neat GBL or DMF solutions of $\mathrm{MAPbI}_{3}$ perovskite $(17 \%$ net 
increase in PCE). ${ }^{[8 d]}$ There is also evidence to suggest that ageing the precursor solution before casting could be beneficial. ${ }^{[30]}$

\subsection{Solvent Engineering}

A key breakthrough in improving the efficiencies of perovskite solar cells came from the group of Sang Il Seok, who employed a "solvent engineering" technique (Figure $3 \mathrm{a}$ ) to deposit $\mathrm{MAPb}\left(\mathrm{I}_{(1-x)} \mathrm{Br}_{x}\right)_{3}$ onto thin mesoporous $\mathrm{TiO}_{2}$ scaffolds. ${ }^{[7]}$ They used a mixture of GBL and DMSO (7:3 v/ v) as a co-solvent for the precursors, where the more volatile solvent (i.e. GBL) evaporates during spin-coating. Subsequently, toluene was deposited on the film during spincoating. The precise mechanism is not yet clear, but presumably the "nonsolvent" for the perovskite constituents causes the salts to rapidly precipitate out of solution into a smooth precrystallized film, potentially consisting of a MAI-PbI ${ }_{2}^{-}$ DMSO intermediate phase. As a final step, annealing at $100^{\circ} \mathrm{C}$ for $10 \mathrm{~min}$ led to the formation of the $\mathrm{MAPbI}_{3}$ perovskite by driving out the entrapped (or coordinated) DMSO. This procedure resulted in compact and uniform capping layers with grain sizes in the range of 100 to $500 \mathrm{~nm}$ with a $100 \%$ surface coverage of the substrate (Figure $3 \mathrm{~b}$ ). These features resulted in the fabrication of solar cells with certified efficiencies of $16.2 \%$, and we suspect that a similar technique but further advanced (including the use of a blend of methylammonium lead bromide and formamidinium lead iodide perovskites $)^{[49]}$ has resulted in certified efficiencies of $20.1 \%$. $^{[3 e]}$

Likewise, Spiccia and co-workers fabricated planar heterojunction solar cells with an average PCE of $13.9 \%$ (with a maximum PCE at $16.2 \%$ ), accompanied by high reproducibility (mean deviation of $0.7 \%$ ), by employing a fast deposition-crystallization (FDC) procedure, ${ }^{[31]}$ which is almost identical to that used by Il Seok, apart from chlorobenzene being employed as the nonsolvent. As Spiccia et al. did not employ DMSO, the perovskite film instantly crystallized when the perovskite constituents precipitated out, evidenced by the instant darkening of the film. The obtained crystalline grains spanned the thickness of the film (approximately micrometer size), being large and free of boundaries in the perpendicular direction, thus allowing for full coverage of the substrate. Our experience is that the method of Spiccia et al. produces films with an impressive mirror-like reflection.

In a different approach, Xiao et al. introduced vapors of DMF during annealing in order to provide a solvent-swollen environment so that the precursor ions could more effectively diffuse compared with all-solid-state thermal annealing. ${ }^{[32]}$ The authors prepared films using two-step deposition and further treated (or not) the perovskite with vapors of DMF during annealing at $100^{\circ} \mathrm{C}$ for 1 hour. Indeed, the observed differences were spectacular; the grain size of the solventannealed films grew much faster than the thermally annealed films. This technique led to solvent-annealed films with a)

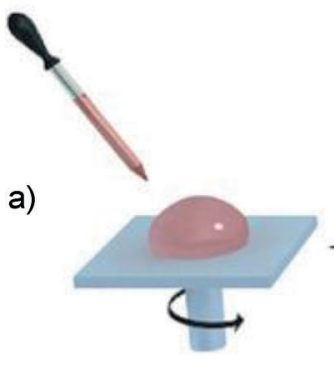

Perovskite solution spreading

b)

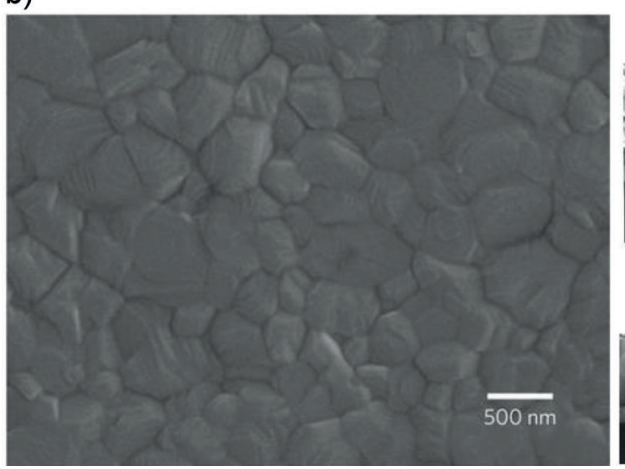

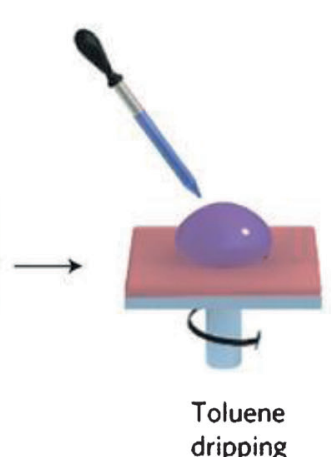

dripping

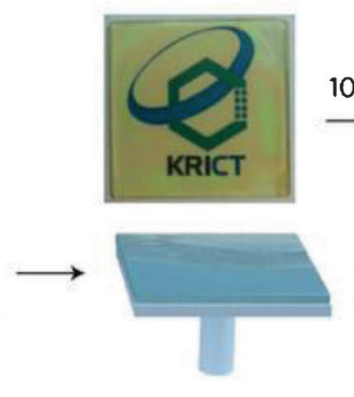

Intermediate phase film
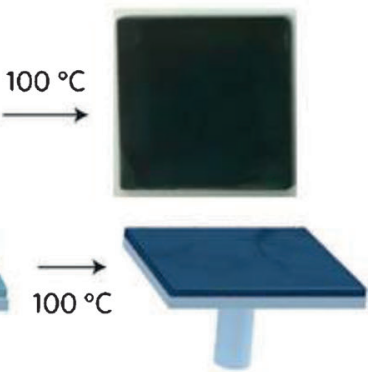

Dense and uniform perovskite film
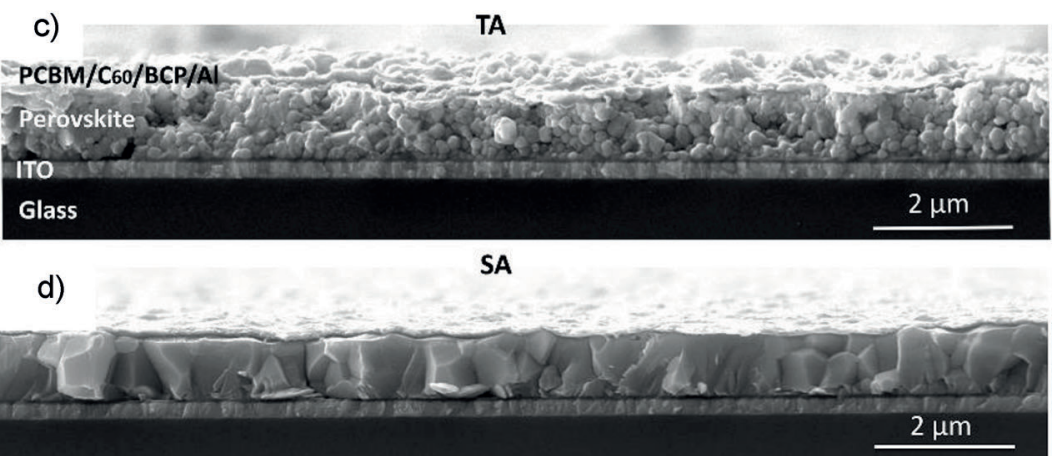

Figure 3. a) Schematic of the solvent-engineering technique and b) top-view SEM image of the resulting $M A P b\left(I_{(1-x)} B r_{x}\right)_{3}$ perovskite film. Reprinted with permission from Macmillan Publishers Ltd: Nature Materials, ${ }^{[7]}$ copyright 2014. c,d) Cross-sectional SEM images of inverted planar heterojunction solar cells with the perovskite produced by c) standard thermal annealing (TA) and d) solvent annealing (SA). Reprinted from Ref. [32]. 
average grain sizes that were consistently larger and more comparable to the film thickness (Figure $3 \mathrm{~d}$ ) than those of the thermally-annealed films (Figure $3 \mathrm{c}$ ). Finally, this method resulted in $630 \mathrm{~nm}$ thick solvent-annealed inverted solar cells with efficiencies of $15.6 \%$, which is substantially higher than those attained by the thermally annealed devices $(9.9 \%)$. A similar approach was employed by C.-H. Chiang et al., who treated both $\mathrm{PC}_{71} \mathrm{BM}$ and the perovskite with solvent vapors by simply covering the perovskite/ $\mathrm{PC}_{71} \mathrm{BM}$ film with a Petri dish with a solvent atmosphere for $24 \mathrm{~h}$. Again, the efficiencies of the inverted solar cells were excellent, reaching up to $16.3 \%$. ${ }^{[33]}$

Recently, Yang and co-workers fabricated planar heterojunction solar cells with $\mathrm{MAPbI}_{3-x} \mathrm{Cl}_{x}$ perovskite, produced using an enhanced "reconstruction process" under controlledhumidity conditions $(30 \% \text { relative humidity })^{[3 c]} \cdot{ }^{[34]}$ The formation of these films progressed via an intermediate $\mathrm{MAPbCl}_{3}$ phase, which was later consumed. The films were also of higher quality than those produced under dry conditions, as evidenced by longer carrier lifetimes, which suggest suppressed recombination. The positive influence of moisture during the crystallization process on carrier lifetimes has recently also been reported elsewhere. ${ }^{[35]}$ Yang et al. speculate that water aids the formation by partially dissolving reactant species and accelerating mass transport, which is essentially a form of solvent-vapor annealing. Combined with improved interfaces, they reported a PCE of $19.3 \%$. We note that exposure to moisture after film formation is highly detrimental to the perovskite and will lead to degradation. ${ }^{[36]}$

\section{The Role of the Precursors}

\subsection{The Role of Chloride lons in Film Formation}

Lee et al. demonstrated the fabrication of perovskites using $\mathrm{PbCl}_{2}$ and MAI in the precursor solution, ${ }^{[3 \mathrm{~b}]}$ and termed the product $\mathrm{MAPbI}_{3-x} \mathrm{Cl}_{x} \cdot{ }^{[13 \mathrm{a}]}$ In the precursor solution, MAI and $\mathrm{PbCl}_{2}$ were present in a nonstoichiometric ratio of $3: 1$. Topics of debate in recent articles ${ }^{[8 c, 37]}$ included whether any chloride ions remain in the perovskite crystal lattice, how many chloride ions remain in the films, and what the role of chloride ions is in film formation. It was even argued that a formula such as $\mathrm{MAPbI}_{3-x} \mathrm{Cl}_{x}$ should be avoided, as no $\mathrm{Cl}^{-}$ has yet been detected in the crystal lattice. ${ }^{[\mathrm{c}, 38]}$

Recent experimental and theoretical investigations highlighted the crucial role of $\mathrm{Cl}^{-}$in $\mathrm{MAPbI}_{3-x} \mathrm{Cl}_{x}$ perovskite solar cells. $^{[3 \mathrm{~b}, 6 \mathrm{a}, 25]}$ Measurements have shown that the perovskite films that were fabricated using the $\mathrm{PbCl}_{2}$ /MAI precursors to form $\mathrm{MAPbI}_{3-x} \mathrm{Cl}_{x}$ have significantly longer charge-carrier diffusion lengths $(>1 \mu \mathrm{m})$ than their triiodide $\left(\mathrm{MAPbI}_{3}\right)$ counterparts $(\approx 100 \mathrm{~nm}) .^{[6 a, b, d]}$ As the observed band gap remains more or less unchanged for the triiodide and "mixedhalide" films, we expect that, if any, there is only a small amount of $\mathrm{Cl}^{-}$present in the lattice of the final absorber material. From experimental and theoretical work, Colella et al. proposed that, at best, only $2-3 \%$ of the $\mathrm{Cl}^{-}$ions can be included in the lattice of a mixed-halide-based absorber material. ${ }^{[39]}$ From angle-resolved X-ray photoelectron spec- troscopy (AR-XPS) measurements, the authors suggest that the $\mathrm{Cl}^{-}$ions are preferentially positioned at the interface of $\mathrm{TiO}_{2}$ and perovskite. ${ }^{[40]}$ Williams et al. used a thermal analysis coupled with Fourier transform infrared (FTIR) spectroscopy to show that films prepared from the mixed-halide precursor solution (i.e. $\mathrm{PbCl}_{2}$ and MAI in DMF) contain some $\mathrm{Cl}^{-}$ions and that the thermal properties are different from those of the stoichiometric $\mathrm{MAPbI}_{3}$ film. ${ }^{[41]} \mathrm{D}^{\prime}$ Innocenzo demonstrated that the tetragonal to orthorhombic phase-transition temperature for the triiodide and mixed-halide perovskite differed by $30 \mathrm{~K}^{\left[{ }^{[12 c]}\right.}$ In light of the above findings, we suggest that we should use the formula $\mathrm{MAPbI}_{3-\mathrm{x}} \mathrm{Cl}_{x}$ for the films prepared from the mixed-halide solutions. However, the quantitative determination of the ratio of $\mathrm{Cl}^{-}$to $\mathrm{I}^{-}$and their optimal ratio for solar-cell applications is yet to be determined. In addition, whether $\mathrm{Cl}^{-}$is predominantly present as a substituent for $\mathrm{I}^{-}$, as an interstitial, or at the surface of the crystal, remains unclear. Initial attempts to detect $\mathrm{Cl}^{-}$by techniques such as energy-dispersive X-ray spectroscopy (EDX), electron-energy-loss spectroscopy (EELS) or surface-sensitive X-ray photoelectron spectroscopy (XPS) failed to detect the presence of $\mathrm{Cl}^{-}$, as the amount was beyond the detectable limit of the technique and/or the techniques probed the bulk sample. ${ }^{[25,38,40]}$

Though it is becoming clear that $\mathrm{Cl}^{-}$ions are present in small amounts at the interface of $\mathrm{TiO}_{2}$ and perovskite, it is not yet clear what happens to the remaining $\mathrm{Cl}^{-}$ions that are included in the precursor solution, and how $\mathrm{Cl}^{-}$ions affect the film formation. Through a combination of thermal, structural, and chemical characterization methods, Yu et al. investigated the role of $\mathrm{Cl}^{-}$ions in the formation of $\mathrm{MAPbI}_{3-x} \mathrm{Cl}_{x}$ films. ${ }^{[42]}$ They found that most of the $\mathrm{Cl}^{-}$ions leave the matrix as gaseous $\mathrm{MACl}$ during the annealing procedure, while the formation of the mixed-halide phase occurs via an intermediate organic-inorganic mixed-halide phase. The excess of $\mathrm{CH}_{3} \mathrm{NH}_{3}{ }^{+}$that is used in the precursor solution is essential for the formation of large crystal domains, as it slows down the crystal formation process. The presence of $\mathrm{Cl}^{-}$ions facilitates the release of excess $\mathrm{CH}_{3} \mathrm{NH}_{3}{ }^{+}$ions, whereas $\mathrm{CH}_{3} \mathrm{NH}_{3} \mathrm{I}$ is not sufficiently volatile in the thin film.

Furthermore, recent studies have shown that the presence of $\mathrm{Cl}^{-}$ions in the precursor solution lead to nucleation centers that assist perovskite growth. ${ }^{[30,43]}$ Williams et al. showed that the presence of $\mathrm{Cl}^{-}$ions gives rise to a fused $\mathrm{CH}_{3} \mathrm{NH}_{3} \mathrm{PbCl}_{3}$ template phase that seeds and directs the growth of larger crystalline perovskite domains than the triiodide analogue, along with better surface coverage. ${ }^{[30]}$ Tidhar et al. showed that the insoluble $\mathrm{PbCl}_{2}$ forms nanocrystals that act as heterogeneous nucleation centers for the formation of perovskite crystals in solution. ${ }^{[43]}$ We note here that a similar effect was seen in the methylammonium lead bromide systems, where the inclusion of a small quantity of $\mathrm{Cl}^{-}$also improved solar-cell performance when compared to the tribromide counterpart as a result of the better morphology. ${ }^{[11 \mathrm{a}]}$ In addition to the effect on morphology, $\mathrm{Cl}^{-}$ions may also induce band bending at the $\mathrm{TiO}_{2}$ interfaces that improves charge collection efficiency. ${ }^{[40]}$ 


\subsection{The Role of the Anions: Alternative Precursors}

Related to the role of chloride ions, we recently systematically studied the role of the precursor anions in the $\mathrm{Pb}$ source in the crystallization of perovskite thin films. ${ }^{[4]} \mathrm{We}$ found that the anions determine the kinetics of perovskite crystal growth, which in turn affects the film morphology and device performance. As the perovskite precursor solution, we employed the $\mathrm{Pb}$ salts $\mathrm{PbCl}_{2}, \mathrm{PbI}_{2}$, and lead acetate $\left(\mathrm{PbAc}_{2}\right)$, each dissolved in DMF with a three-fold excess of MAI. The precursor solutions were then spin-coated and the substrates were annealed. All processing routes led to the formation of a material that is predominantly $\mathrm{MAPbI}_{3}$, but with considerably different properties of the thin films. The perovskite films prepared from $\mathrm{PbCl}_{2}$ (Figure $4 \mathrm{a}$ ) and $\mathrm{PbI}_{2}$ (Figure 4b)

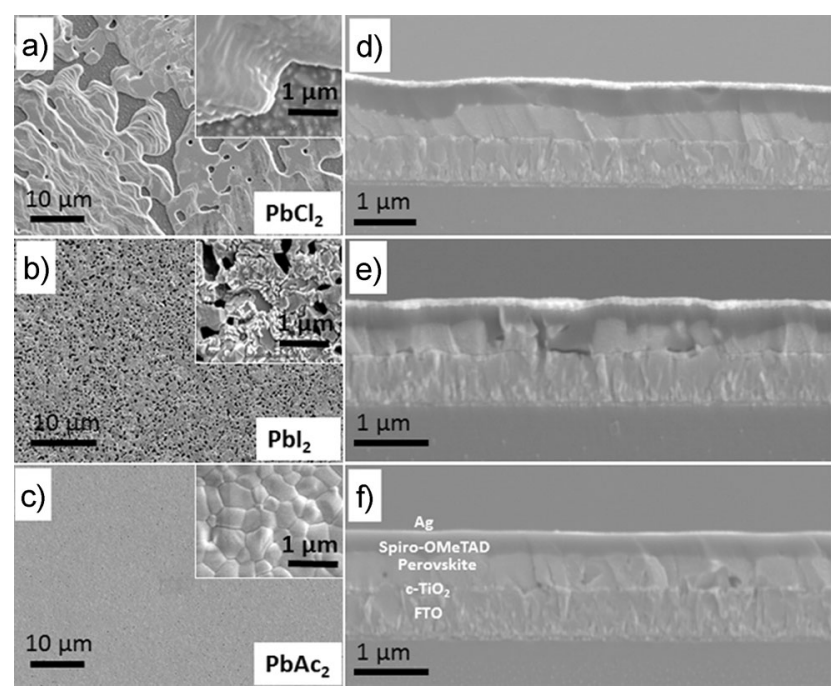

Figure 4. SEM images of perovskite films deposited on $\mathrm{FTO} / \mathrm{c}-\mathrm{TiO}_{2}$ substrates from the three different $\mathrm{Pb}$ sources: a) $\mathrm{PbCl}_{2}$, b) $\mathrm{Pbl}_{2}$, and c) $\mathrm{PbAc}_{2}$, (insets show images with higher resolution); cross-sections of full devices with the perovskite derived from d) $\mathrm{PbCl}_{2}$, e) $\mathrm{Pbl}_{2}$, and f) $\mathrm{PbAc}_{2}$. Reprinted with permission from Macmillan Publishers Ltd: Nature Communications, ${ }^{[44]}$ copyright 2015.

are noncontinuous, with pinholes of different lengths and no clear grain boundaries of the crystals. By contrast, the perovskite films derived from $\mathrm{PbAc}_{2}$ (Figure 4c) exhibit a considerably different morphology, attaining almost full coverage on the substrates with crystal grain sizes in the range 100-1000 nm (Figure 4c, inset). In addition, the cross-sectional SEM images clearly show that the perovskite films obtained through the $\mathrm{PbAc}_{2}$ route are much smoother (Figure $4 \mathrm{f}$ ) than the films prepared from $\mathrm{PbCl}_{2}$ (Figure 4d) and $\mathrm{PbI}_{2}$ (Figure 4e). We quantified this smoothness using atomic force microscopy (AFM), which showed that the rootmean-square roughness of the perovskite films prepared from $\mathrm{PbCl}_{2}, \mathrm{PbI}_{2}$, and $\mathrm{PbAc}_{2}$ is $62.4,52.2$ and $12.3 \mathrm{~nm}$, respectively. Remarkably, the films prepared from $\mathrm{PbAc}_{2}$ are smoother than those of the dual-source vapor-deposited films prepared from $\mathrm{PbCl}_{2}(16.2 \mathrm{~nm})$, which had until now resulted in much smoother and more continuous films than solution coating. Sargent and co-workers have also observed similar results when comparing $\mathrm{PbI}_{2}$ and $\mathrm{PbAc}_{2}$, consistent with our findings. ${ }^{[45]}$

In order to achieve the best device performance, the perovskite films prepared from $\mathrm{PbCl}_{2}$ and $\mathrm{PbI}_{2}$ needed to be annealed for $2 \mathrm{~h}$ at $100^{\circ} \mathrm{C}$ and $40 \mathrm{~min}$ at $150^{\circ} \mathrm{C}$, respectively. However, the optimized annealing time was much shorter for the films prepared from $\mathrm{PbAc}_{2}\left(5 \mathrm{~min}\right.$ at $\left.100^{\circ} \mathrm{C}\right)$, which is consistent with the much more facile removal of excess MAAc during crystallization compared with the removal of $\mathrm{MACl}$ or MAI. The average PCE of complete solar cells constructed with perovskites that were prepared with optimized annealing times from $\mathrm{PbCl}_{2}, \mathrm{PbI}_{2}$, and $\mathrm{PbAc}_{2}$ were 12.0, 9.3 , and $14.0 \%$, respectively. Therefore, by using $\mathrm{PbAc}_{2}$ as the $\mathrm{Pb}$ source, we have achieved a much faster and more uniform crystallization compared with the other two routes, and thus improved device performance. The $\mathrm{PbAc}_{2}$ route offers the possibility of employing precursor salts that do not only contain the eventual perovskite components. This implies that a much broader range of precursors can be investigated, with the "spectator ions" chosen for properties that can enhance or control processing, thin-film formation, and crystallization.

\section{Summary and Outlook}

Methods for the formation of organic-inorganic perovskite films have evolved significantly since the first reports of $2 \mathrm{~nm}$ sized nanoparticles coated upon a mesoporous $\mathrm{TiO}_{2}$ electrode in 2009. ${ }^{[3 a]}$ The quality of the films resulting from simple solution processing, in which the precursors are dissolved in a single organic solvent ${ }^{[3 \mathrm{~b}, \mathrm{~d}]}$, has been surpassed by a variety of optimizations and alternative methods, such as two-step conversions. For high-performance planar heterojunction solar cells, it is essential to have nearly complete surface coverage to prevent both low-resistance shunting paths between the n- and p-type contacts, as well as low light absorption in the solar cell. This goal can be achieved using optimized spin-coating and annealing, ${ }^{[15]}$ co-evaporation, ${ }^{[17]}$ and two-step methods including solvent ${ }^{[13 c, 24]}$ and vapor ${ }^{[20]}$ conversions, interdiffusion, ${ }^{[19,28]}$ and post treatments, such as solvent-vapor annealing. ${ }^{[3 c, 32,33]}$ Aside from continuous films, large crystalline domains are desirable and can also be achieved using many of these methods. Our interpretation of the results from the various methods is that the induction of fast crystallization promotes near perfect surface coverage, while slower crystallization promotes the growth of larger crystals, but with generally lower coverage. The highest quality films (and highest published certified PCE) have been obtained using "solvent engineering" techniques, ${ }^{[7,31,49]}$ whereby crystallization is optimized by exploiting relative volatilities and binding abilities of various solvents and reactants. This technique appears to be a very promising route for producing high-quality crystalline films.

The presence of chloride ions in the "mixed-halide" perovskite films, formed from $\mathrm{MAI} / \mathrm{PbCl}_{2}$ precursors, has been the subject of debate for some time. ${ }^{[3 \mathrm{~b}, 8 c]}$ While it is likely that chloride ions are only present in the lattice in tiny amounts (beyond the detection limit of many techniques), physical differences have been observed between that prod- 
uct and $\mathrm{MAPbI}_{3},{ }^{[40]}$ justifying the mixed-halide formula of $\mathrm{MAPbI}_{3-x} \mathrm{Cl}_{x}$ (with $x$ being small and to be defined, and no doubt varying between preparation routes). It is becoming clear that the excess $\mathrm{CH}_{3} \mathrm{NH}_{3}{ }^{+}$and the presence of $\mathrm{Cl}^{-}$ primarily assists in film formation, leading to planar films with generally superior properties compared to their triiodide counterparts. This role in film formation is not unique to chloride ions; we have shown that the acetate anion in the precursor can also lead to ultrasmooth films of very high quality, ${ }^{[44]}$ but other spectator anions might lead to even more improved film formation.

Perovskites have been shown to have low intergrain potential barriers. ${ }^{[46]}$ Nevertheless, several recent reports have shown that there is a significant subgap trap density that plays a crucial role in recombination. ${ }^{[6,45,47]}$ The origin of the traps is as yet unclear, but they could arise from vacancies through the bulk or on crystal surfaces. Suitable surface treatments can passivate these sites to a certain extent, but not entirely. ${ }^{[48]}$ Aside from the further optimization of film morphology, the prevention of the formation of these trap states, or at least minimizing their influence, will be key to future advances in device performances. It is our understanding that the continued increase in the domain size of crystals and the uniformity of thin-film deposition will be the main factors that will increase the performance of perovskite solar cells over the next few years.

The research leading to these results has received funding from the European Union Seventh Framework Programme (FP7/ 2007-2013) under grant agreement no. 604032 of the MESO project and the Engineering and Physical Sciences Research Council (EPSRC). The authors thank M. Saliba and S. M. Hein for preparing the table-of-contents figure, and M. Liu for providing XRD data.

Received: October 17, 2014

Published online: February 6, 2015

[1] International Energy Agency (IEA) 2014

[2] S. Chu, A. Majumdar, Nature 2012, 488, 294-303.

[3] a) A. Kojima, K. Teshima, Y. Shirai, T. Miyasaka, J. Am. Chem. Soc. 2009, 131, 6050; b) M. M. Lee, J. Teuscher, T. Miyasaka, T. N. Murakami, H. J. Snaith, Science 2012, 338, 643-647; c) H Zhou, Q. Chen, G. Li, S. Luo, T.-b. Song, H.-S. Duan, Z. Hong, J. You, Y. Liu, Y. Yang, Science 2014, 345, 542-546; d) H. S. Kim, C. R. Lee, J. H. Im, K. B. Lee, T. Moehl, A. Marchioro, S. J. Moon, R. Humphry-Baker, J. H. Yum, J. E. Moser, M. Gratzel, N. G. Park, Sci. Rep. 2012, 2, 591; e) National Renewable Energy Labs (NREL) Efficiency Chart 2014, http://www.nrel.gov/ncpv/ images/efficiency_chart.jpg.

[4] M. A. Green, K. Emery, Y. Hishikawa, W. Warta, E. D. Dunlop, Prog. Photovoltaics 2014, 22, 701-710.

[5] a) S. De Wolf, J. Holovsky, S.-J. Moon, P. Löper, B. Niesen, M. Ledinsky, F.-J. Haug, J.-H. Yum, C. Ballif, J. Phys. Chem. Lett. 2014, 5, 1035-1039; b) A. Sadhanala, F. Deschler, T. H. Thomas, S. E. Dutton, K. C. Goedel, F. C. Hanusch, M. L. Lai, U. Steiner, T. Bein, P. Docampo, D. Cahen, R. H. Friend, J. Phys. Chem. Lett. 2014, 5, 2501-2505.

[6] a) S. D. Stranks, G. E. Eperon, G. Grancini, C. Menelaou, M. J. Alcocer, T. Leijtens, L. M. Herz, A. Petrozza, H. J. Snaith, Science 2013, 342, 341-344; b) G. Xing, N. Mathews, S. Sun, S. S.
Lim, Y. M. Lam, M. Grätzel, S. Mhaisalkar, T. C. Sum, Science 2013, 342, 344-347; c) C. Wehrenfennig, G. E. Eperon, M. B. Johnston, H. J. Snaith, L. M. Herz, Adv. Mater. 2014, 26, $1584-$ 1589; d) E. Edri, S. Kirmayer, S. Mukhopadhyay, K. Gartsman, G. Hodes, D. Cahen, Nat. Commun. 2014, 5, 3461.

[7] N. J. Jeon, J. H. Noh, Y. C. Kim, W. S. Yang, S. Ryu, S. I. Seok, Nat. Mater. 2014, 13, 897-903.

[8] a) H. J. Snaith, J. Phys. Chem. Lett. 2013, 4, 3623-3630; b) M. A. Green, A. Ho-Baillie, H. J. Snaith, Nat. Photonics 2014, 8, $506-$ 514; c) M. Grätzel, Nat. Mater. 2014, 13, 838-842; d) H. J. Snaith, A. Abate, J. M. Ball, G. E. Eperon, T. Leijtens, N. K. Noel, S. D. Stranks, J. T. W. Wang, K. Wojciechowski, W. Zhang, J. Phys. Chem. Lett. 2014, 5, 1511-1515.

[9] a) G. E. Eperon, S. D. Stranks, C. Menelaou, M. B. Johnston, L. M. Herz, H. J. Snaith, Energy Environ. Sci. 2014, 7, 982; b) A. Mei, X. Li, L. Liu, Z. Ku, T. Liu, Y. Rong, M. Xu, M. Hu, J. Chen, Y. Yang, M. Grätzel, H. Han, Science 2014, 345, 295-298; c) F. C. Hanusch, E. Wiesenmayer, E. Mankel, A. Binek, P. Angloher, C. Fraunhofer, N. Giesbrecht, J. M. Feckl, W. Jaegermann, D. Johrendt, T. Bein, P. Docampo, J. Phys. Chem. Lett. 2014, 5, 2791-2795; d) T. M. Koh, K. Fu, Y. Fang, S. Chen, T. C. Sum, N. Mathews, S. G. Mhaisalkar, P. P. Boix, T. Baikie, J. Phys. Chem. C 2014, 118, 16458-16462; e) J. W. Lee, D. J. Seol, A. N. Cho, N. G. Park, Adv. Mater. 2014, 26, 4991-4998.

[10] a) N. K. Noel, S. D. Stranks, A. Abate, C. Wehrenfennig, S. Guarnera, A. A. Haghighirad, A. Sadhanala, G. E. Eperon, S. K. Pathak, M. B. Johnston, A. Petrozza, L. M. Herz, H. J. Snaith, Energy Environ. Sci. 2014, 7, 3061-3068; b) F. Hao, C. C. Stoumpos, D. H. Cao, R. P. H. Chang, M. G. Kanatzidis, Nat. Photonics 2014, 8, 489-494.

[11] a) E. Edri, S. Kirmayer, M. Kulbak, G. Hodes, D. Cahen, J. Phys. Chem. Lett. 2014, 5, 429-433; b) E. Edri, S. Kirmayer, D. Cahen, G. Hodes, J. Phys. Chem. Lett. 2013, 4, 897-902.

[12] a) T. Baikie, Y. N. Fang, J. M. Kadro, M. Schreyer, F. X. Wei, S. G. Mhaisalkar, M. Graetzel, T. J. White, J. Mater. Chem. A 2013, 1, 5628-5641; b) T. Ishihara, J. Takahashi, T. Goto, Phys. Rev. B 1990, 42, 11099-11107; c) V. D'Innocenzo, G. Grancini, M. J. Alcocer, A. R. Kandada, S. D. Stranks, M. M. Lee, G. Lanzani, H. J. Snaith, A. Petrozza, Nat. Commun. 2014, 5, 3586.

[13] a) J. M. Ball, M. M. Lee, A. Hey, H. J. Snaith, Energy Environ. Sci. 2013, 6, 1739-1743; b) J. H. Heo, S. H. Im, J. H. Noh, T. N. Mandal, C. S. Lim, J. A. Chang, Y. H. Lee, H. J. Kim, A. Sarkar, M. K. Nazeeruddin, M. Grätzel, S. I. Seok, Nat. Photonics 2013, 7, 486-491; c) J. Burschka, N. Pellet, S. J. Moon, R. HumphryBaker, P. Gao, M. K. Nazeeruddin, M. Gratzel, Nature 2013, 499, 316-319.

[14] V. M. Burlakov, G. E. Eperon, H. J. Snaith, S. J. Chapman, A. Goriely, Appl. Phys. Lett. 2014, 104, 091602.

[15] G. E. Eperon, V. M. Burlakov, P. Docampo, A. Goriely, H. J. Snaith, Adv. Funct. Mater. 2014, 24, 151-157.

[16] M. Saliba, K. W. Tan, H. Sai, D. T. Moore, T. Scott, W. Zhang, L. A. Estroff, U. Wiesner, H. J. Snaith, J. Phys. Chem. C 2014, 118, 17171-17177.

[17] M. Liu, M. B. Johnston, H. J. Snaith, Nature 2013, 501, 395-398.

[18] M. Era, T. Hattori, T. Taira, T. Tsutsui, Chem. Mater. 1997, 9, 8 10.

[19] Z. G. Xiao, C. Bi, Y. C. Shao, Q. F. Dong, Q. Wang, Y. B. Yuan, C. G. Wang, Y. L. Gao, J. S. Huang, Energy Environ. Sci. 2014, 7, $2619-2623$

[20] H. Tian, B. Xu, H. Chen, E. M. Johansson, G. Boschloo, ChemSusChem 2014, 7, 2150-2153.

[21] A. T. Barrows, A. J. Pearson, C. K. Kwak, A. D. F. Dunbar, A. R. Buckley, D. G. Lidzey, Energy Environ. Sci. 2014, 7, $2944-2950$.

[22] K. Liang, D. B. Mitzi, M. T. Prikas, Chem. Mater. 1998, 10, $403-$ 411.

[23] J. Burschka, PhD Thesis, École Polytechnique Fédérale de Lausanne 2013. 
[24] D. Liu, T. L. Kelly, Nat. Photonics 2014, 8, 133-138.

[25] P. Docampo, F. C. Hanusch, S. D. Stranks, M. Döblinger, J. M. Feckl, M. Ehrensperger, N. K. Minar, M. B. Johnston, H. J. Snaith, T. Bein, Adv. Energy Mater. 2014, 4, 1400355.

[26] Y. Wu, A. Islam, X. Yang, C. Qin, J. Liu, K. Zhang, W. Peng, L. Han, Energy Environ. Sci. 2014, 7, 2934.

[27] C. W. Chen, H. W. Kang, S. Y. Hsiao, P. F. Yang, K. M. Chiang, H. W. Lin, Adv. Mater. 2014, 26, 6647-6652.

[28] J. H. Im, I. H. Jang, N. Pellet, M. Gratzel, N. G. Park, Nat. Nanotechnol. 2014, 9, 927-932.

[29] P. W. Liang, C. Y. Liao, C. C. Chueh, F. Zuo, S. T. Williams, X. K. Xin, J. Lin, A. K. Jen, Adv. Mater. 2014, 26, 3748-3754.

[30] S. T. Williams, F. Zuo, C. C. Chueh, C. Y. Liao, P. W. Liang, A. K. Jen, ACS Nano 2014, 8, 10640-10654.

[31] M. Xiao, F. Huang, W. Huang, Y. Dkhissi, Y. Zhu, J. Etheridge, A. Gray-Weale, U. Bach, Y. B. Cheng, L. Spiccia, Angew. Chem. Int. Ed. 2014, 53, 9898-9903; Angew. Chem. 2014, 126, $10056-$ 10061.

[32] Z. Xiao, Q. Dong, C. Bi, Y. Shao, Y. Yuan, J. Huang, Adv. Mater. 2014, 26, 6503-6509.

[33] C.-H. Chiang, Z.-L. Tseng, C.-G. Wu, J. Mater. Chem. A 2014, 2 , $15897-15903$

[34] J. You, Y. Yang, Z. Hong, T.-B. Song, L. Meng, Y. Liu, C. Jiang, H. Zhou, W.-H. Chang, G. Li, Y. Yang, Appl. Phys. Lett. 2014, 105, 183902.

[35] K. K. Bass, R. E. McAnally, S. Zhou, P. I. Djurovich, M. E. Thompson, B. C. Melot, Chem. Commun. 2014, 50, 15819 15822 .

[36] J. H. Noh, S. H. Im, J. H. Heo, T. N. Mandal, S. I. Seok, Nano Lett. 2013, 13, 1764-1769.

[37] S. A. Bretschneider, J. Weickert, J. A. Dorman, L. SchmidtMende, APL Mater. 2014, 2, 040701.

[38] M. I. Dar, N. Arora, P. Gao, S. Ahmad, M. Gratzel, M. K. Nazeeruddin, Nano Lett. 2014, DOI: 10.1021/n1503279x.

[39] S. Colella, E. Mosconi, P. Fedeli, A. Listorti, F. Gazza, F. Orlandi, P. Ferro, T. Besagni, A. Rizzo, G. Calestani, G. Gigli, F. De Angelis, R. Mosca, Chem. Mater. 2013, 25, 4613-4618.
[40] S. Colella, E. Mosconi, G. Pellegrino, A. Alberti, V. L. P. Guerra, S. Masi, A. Listorti, A. Rizzo, G. G. Condorelli, F. De Angelis, G. Gigli, J. Phys. Chem. Lett. 2014, 5, 3532-3538.

[41] A. E. Williams, P. J. Holliman, M. J. Carnie, M. L. Davies, D. A. Worsley, T. M. Watson, J. Mater. Chem. A 2014, 2, 19338-19346.

[42] H. Yu, F. Wang, F. Xie, W. Li, J. Chen, N. Zhao, Adv. Funct. Mater. 2014, 24, 7102-7710.

[43] Y. Tidhar, E. Edri, H. Weissman, D. Zohar, G. Hodes, D. Cahen, B. Rybtchinski, S. Kirmayer, J. Am. Chem. Soc. 2014, 136, 13249-13256.

[44] W. Zhang, M. Saliba, D. T. Moore, S. Pathak, M. T. Hoerantner, T. Stergiopoulos, S. D. Stranks, G. E. Eperon, J. A. AlexanderWebber, A. Abate, A. Sadhanala, S. Yao, Y. Chen, R. H. Friend, L. A. Estroff, U. Wiesner, H. J. Snaith, Nat. Commun. 2015, DOI: $10.1038 /$ ncomms7142.

[45] A. Buin, P. Pietsch, J. Xu, O. Voznyy, A. H. Ip, R. Comin, E. H. Sargent, Nano Lett. 2014, 14, 6281-6286.

[46] E. Edri, S. Kirmayer, A. Henning, S. Mukhopadhyay, K. Gartsman, Y. Rosenwaks, G. Hodes, D. Cahen, Nano Lett. 2014, 14, 1000-1004.

[47] a) S. D. Stranks, V. M. Burlakov, T. Leijtens, J. M. Ball, A. Goriely, H. J. Snaith, Phys. Rev. Applied 2014, 2, 034007; b) T. Leijtens, S. D. Stranks, G. E. Eperon, R. Lindblad, E. M. Johansson, I. J. McPherson, H. Rensmo, J. M. Ball, M. M. Lee, H. J. Snaith, ACS Nano 2014, 8, 7147-7155; c) G. Xing, N. Mathews, S. S. Lim, N. Yantara, X. Liu, D. Sabba, M. Gratzel, S. Mhaisalkar, T. C. Sum, Nat. Mater. 2014, 13, 476-480; d) J. Kim, S.-H. Lee, J. H. Lee, K.-H. Hong, J. Phys. Chem. Lett. 2014, 5, $1312-1317$; e) W.-J. Yin, T. Shi, Y. Yan, Appl. Phys. Lett. 2014, 104,063903

[48] a) N. K. Noel, A. Abate, S. D. Stranks, E. S. Parrott, V. M. Burlakov, A. Goriely, H. J. Snaith, ACS Nano 2014, 8, $9815-$ 9821; b) A. Abate, M. Saliba, D. J. Hollman, S. D. Stranks, K. Wojciechowski, R. Avolio, G. Grancini, A. Petrozza, H. J. Snaith, Nano Lett. 2014, 14, 3247-3254.

[49] N. J. Jeon, J. H. Noh, W. S. Yang, Y. C. Kim, S. Ryu, J. Seo, S. I. Seok, Nature 2015, DOI: 10.1038/nature14133. 